\title{
The Clinical and Biological Effects of Homeopathically Prepared Signaling Molecules: A Scoping Review
}

\author{
Raj Kumar Manchanda ${ }^{1} \quad$ Meeta Gupta $^{1}$ Ankit Gupta ${ }^{1}$ Robbert van Haselen ${ }^{2}$ \\ ${ }^{1}$ Directorate of AYUSH, Health \& Family Welfare Department, Govt of \\ Delhi, New Delhi, India \\ 2 International Institute for Integrated Medicine, Kingston, United \\ Kingdom \\ Address for correspondence Robbert van Haselen, MSc, International \\ Institute for Integrated Medicine, Suite 467, 29 Castle Street, \\ Kingston KT1 1DN, United Kingdom \\ (e-mail: vanhaselen@intmedi.com).
}

Homeopathy 2022;111:10-21.

\begin{abstract}
Keywords

- cytokines

- specific nucleic acids

- low dose medicine

- signaling molecules

Background Signaling molecules such as cytokines and interleukins are key mediators for the immune response in responding to internal or external stimuli. Homeopathically prepared signaling molecules have been used therapeutically for about five decades. However, these types of products are not available in many countries and their usage by homoeopaths is also infrequent. The aim of this scoping review is to map the available pre-clinical and clinical data related to the therapeutic use of homeopathically prepared signaling molecules.

Methods We conducted a scoping review of clinical and pre-clinical studies of therapeutically used signaling molecules that have been prepared in accordance with an officially recognized homeopathic pharmacopoeia. Articles in peer-reviewed journals reporting original clinical or pre-clinical research of homeopathically prepared signaling molecules such as interleukins, cytokines, antibodies, growth factors, neuropeptides and hormones, were eligible. Non-English language papers were excluded, unless we were able to obtain an English translation. An appraisal of eligible studies took place by rating the direction of the outcomes on a five-point scale. The quality of the papers was not systematically assessed.

Results Twenty-eight eligible papers, reporting findings for four different manufacturers' products, were identified and reviewed. Seventeen papers reported pre-clinical studies, and 11 reported clinical studies (six experimental, five observational). A wide range of signaling molecules, as well as normal T-cell expressed specific nucleic acids, were used. A majority of the products (21 of 28 ) contained two or more signaling molecules. The most common clinical indications were psoriasis, vitiligo, rheumatoid arthritis, respiratory allergies, polycystic ovary syndrome, and herpes. The direction of the outcomes was positive in 26 papers and unclear in two papers.

Conclusion This scoping review found that there is a body of evidence on the use of homeopathically prepared signaling molecules. From a homeopathy perspective, these substances appear to have therapeutic potential. Further steps to explore this potential are warranted.
\end{abstract}

received

March 23, 2021

accepted after revision

June 4, 2021

published online

November 19, 2021
DOI https://doi.org/ 10.1055/s-0041-1732305. ISSN 1475-4916.

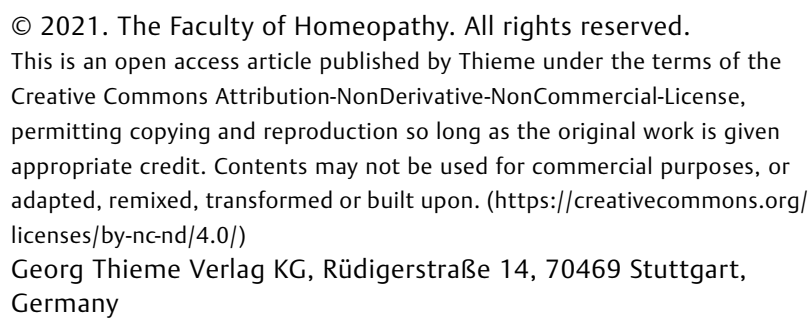




\section{Introduction}

Signaling molecules such as cytokines and interleukins are key mediators for the immune response in responding to internal or external stimuli. In biology, information in molecular structures-the chemical properties of molecules that enable them to recognize and bind to one another-is central to the function of all processes. Signaling molecules are essential for the cross-talk between the psychological, neurological, endocrinological and immunological systems that form the psycho-neuro-endocrino-immunological network. This network is responsible for maintaining homeostasis, and correspondingly, a loss in the homeostatic equilibrium of signaling molecules can lead to the onset of various pathologies, including inflammatory, allergic and autoimmune diseases. This fits well into an emerging systemic view of life, which considers the presence of several interconnected features such as response to stress via hormetic regulation, maintenance of homeostasis and spatial compartmentalization to be the key hallmarks of human health. ${ }^{1}$

A core principle of homeopathy is the stimulation of selfregulation in diseased individuals via the administration of homeopathically prepared medicinal products based on the Principle of Similars. Consistent with the latter principle, the same substance can have inverse effects depending on the dose. Historically, this effect is referred to as the ArndtSchultz principle; ${ }^{2}$ in modern times this phenomenon, also referred to as hormesis, was extensively investigated by Prof. Edward Calabrese, who acknowledged that there is a relation between hormesis and homeopathy. ${ }^{3}$ This type of adaptive response is often characterized by an inverse $J$-shaped doseresponse curve (a low dose stimulates; a higher dose inhibits). Application of homeopathically prepared substances with the aim to stimulate an adaptive response (recovery) after an organism has lost its homeostatic equilibrium is also referred to as "postconditioning hormesis". ${ }^{4}$ This biphasic dose-response is also observed in the functioning of many signaling molecules and can, for instance, explain the mixed agonist/antagonist action of various cytokines. ${ }^{5,6}$

All homeopathic medicinal products have undergone a process known as potentization, which involves stepwise serial dilution alternating with kinetic agitation (e.g., vigorous shaking with impact, also referred to as succussion, serial kinetic activation, etc.). Potentization of substances (involving kinetic agitation during each dilution step) is one of the core characteristics of homeopathically prepared medicinal products. Potentized signaling molecules have been in use for some time now and are available on the market as medicinal products in several countries. Whilst homeopathically prepared, no classical proving data are available. The latter situation is also applicable to many isopathic substances, but this is not a major problem because the conceptual relation between, e.g., the use of homeopathically prepared pollen and the indication hay fever is clear. Various trials on isopathic approaches have further publicized such approaches, ${ }^{7}$ and subsequently these trials have been included in systematic reviews of homeopathy. This is currently less clear for the use of homeopathically prepared signaling molecules. On one hand, such products are defined by the WHO as homeopathic medicinal products if prepared in accordance with one of the recognized homeopathic pharmacopoeias. ${ }^{8}$ On the other hand, there is a need to further clarify and communicate the relationship between the use of these products and homeopathy as a therapeutic system. The latter will also contribute toward further clarity on the regulatory status of such novel products in several countries, and thereby ensure or enhance market access.

There is currently a lack of awareness and understanding in the homeopathy community about the use and therapeutic position of potentized signaling molecules. To date, both clinical and pre-clinical studies on such products have been excluded from reviews, and therefore relatively little is known about the nature and extent of the available data.

Hahnemann developed homeopathy principally as a phenomenological medicinal system. This took place against the background of his justified criticism against mainstream medicine at the time, which was primarily based on the flawed theory of humoral pathology. Hahnemann was, however, firmly dedicated to aligning homeopathy with the natural sciences, but this connection has been weakened during the accelerating pace of scientific discoveries in the 20th and 21st century. In our opinion, it is important for both the recognition and further development of homeopathy that these connections are strengthened.

Signaling molecules are interesting substances because of their pivotal role in the biology of both health and disease. Moreover, these types of substances have been used therapeutically in homeopathy for approximately 50 years. There is a need to further map the available scientific data on these products, with a view to informing more formalized subsequent reviews. There is also a need to further clarify and discuss the homeopathic character and status of such products in the homeopathy community. This will also contribute to addressing the current regulatory policy gap with regard to such products. The aim of this scoping review is to map the available pre-clinical and clinical data on homeopathically prepared signaling molecules and to address the question of their position within the epistemological framework of homeopathy.

\section{Methods}

We conducted a scoping review of clinical and pre-clinical studies of homeopathically prepared signaling molecules that are used therapeutically. "Homeopathically prepared" was defined as being manufactured in accordance with one of the officially recognized homeopathic pharmacopoeias. Signaling molecules were defined as any molecule involved in endocrine, paracrine, autocrine, intracrine, and/or direct signaling. Antibodies were included within this broad definition, because of their involvement in the activation of the complement system via binding sites on the tail of their $Y$ shaped form. Nucleic acids such as DNA and RNA were included as well, because in addition to their main functions of creating, encoding and storing biological information in 
cells, they also serve to transmit and express that information inside and outside the nucleus.

Articles in peer-reviewed journals, reporting original clinical or pre-clinical research of therapeutically used homeopathically prepared signaling molecules, such as interleukins, cytokines, antibodies, growth factors, histamine, neuropeptides and hormones, were eligible. Experimental as well as observational designs, including clinical case reports, were permitted. Since this was a first exploration of the available literature, we decided on a post hoc basis to accept studies on combination products containing signaling molecules plus other homeopathic medicines, and also veterinary studies. English language papers were eligible, as well as non-English language papers of which we were able to obtain an English translation. No restrictions on the year of publication were applied.

The following types of papers were excluded: review articles or opinion pieces not reporting original research; second, similar, publications on the same original study; papers reporting on homeopathically prepared plant hormones in plant-based experimental studies.

Potentially relevant publications were identified by approaching the known manufacturers of homeopathically prepared signaling molecules, and by studying the reference lists of the provided publications. The Scopus abstract and citation database of peer-reviewed literature was used for electronically searching the published literature. While hormesis may help to explain some of the effects observed in association with the low doses used in homeopathy, hormesis does not entail potentization as a specific process for homeopathic medicinal products. So, while "low dose" related terms were used as part of the search strategy to identify potentially eligible papers, only papers involving homeopathically prepared substances were included in this review.

The following search terms were used: low dose, low-dose medicine, low-dose cytokine, low-dose multi-component medication, sequential kinetic activation, SKA, ultra-low dose, ultralow dose, adrenaline/Adrenalinum, Citomix, GUNA-Interleukin, GUNA-FGF, GUNA-Anti-IL, histamine/Histaminum, micro-immunotherapy, 2LARTH, 2LHERP, 2LPARK, 2LPAPI, 2LALERG, and antibody containing preparations. The end date of the literature search was July $31^{\text {st }}, 2020$.

The following variables were collected for each of the identified studies: first author, publication year, journal, study objective(s), type(s) of signaling molecules concerned, research design, clinical domain/application, results, and main conclusions as reported by the authors.

The categories of study designs were pre-defined as follows: randomized clinical trials (double blind, parallel groups, placebo controlled; double blind, placebo controlled; comparative clinical; double blind, placebo-controlled twoperiod crossover; double blind, comparative; double blind, active-controlled; active-controlled); observational studies (prospective case series; case series; prospective non-comparative cohort; prospective comparative cohort; retrospective comparative cohort; retrospective non-comparative cohort; matched pairs); and pre-clinical studies (in vitro, ex vivo; in vitro; in vivo).
An appraisal of all eligible studies took place by rating the direction of the findings as reported in one of the following categories: clearly positive; tentatively positive; unclear; tentatively negative; clearly negative. The quality of the papers was not systematically assessed. The assessment of the direction of the evidence was based on: (1) the conclusions as reported by the authors; (2) the consistency of the results; and (3) the identification of methodological flaws. For instance, a lack of consistency in the results (some test results are significant, while others are nonsignificant) would lead to a downgrading of one category in the assessment of the direction of the evidence. Also, the identification of significant or obvious methodological weaknesses in the paper would lead to an assessment of "unclear", even if the results were reported as positive by the authors.

The papers were independently assessed by all four authors. Consensus on the assessment of the direction of the evidence was reached on the basis of discussion if/as appropriate.

We did not deem it necessary to comprehensively chart the data. Nonetheless, to help with visualizing the direction of outcomes, arrows of three different colors were used. Upward facing vertical green arrows for clearly positive outcomes, upward angled ( 45 degrees) yellow arrows for a tentatively positive direction of the results, a horizontal orange arrow for an unclear direction of the outcomes, and a downward facing red arrow for a tentatively or clearly negative direction of the outcomes. Reporting of this paper follows the PRISMA extension guidelines for scoping reviews. ${ }^{9}$

\section{Results}

The screening process is summarized in -Fig. $\mathbf{1}$.

During pre-screening, 169 papers related to the Russian company Materia Medica Holding were excluded on the grounds that these products were not manufactured in accordance with one of the recognized pharmacopoeias. Nonetheless, their product range contains serially diluted and kinetically agitated purified antibodies against a variety of molecules such as IFN- $\gamma$, TNF-a, prostate-specific antigen, endothelial NO synthase, erythropoietin, S-100 protein, $\beta$-Unit insulin receptor, bradykinin, histamine, morphine, and $\mathrm{CD}-4$ co-receptor.

Eight of the remaining 36 studies were excluded, ${ }^{10-17}$ leaving 17 publications related to GUNA products, ${ }^{18-34}$ eight to LABO'LIFE products, ${ }^{35-42}$ two to Boiron products ${ }^{43,44}$ and one to a product manufactured by Laboratorios Medicor ${ }^{45}$ as the principal basis for this scoping review.

Relevant data from the papers were extracted into two tables: one with the data on the included studies (-Supplementary Table 1, available online only), and a second one with the excluded studies (-Supplementary Table 2, available online only).

The main data on the 28 included papers are summarized in - Table 1.

A wide range of signaling molecules are utilized in the products, as well as normal T-cell expressed specific nucleic acids consisting of very short single strands of DNA 


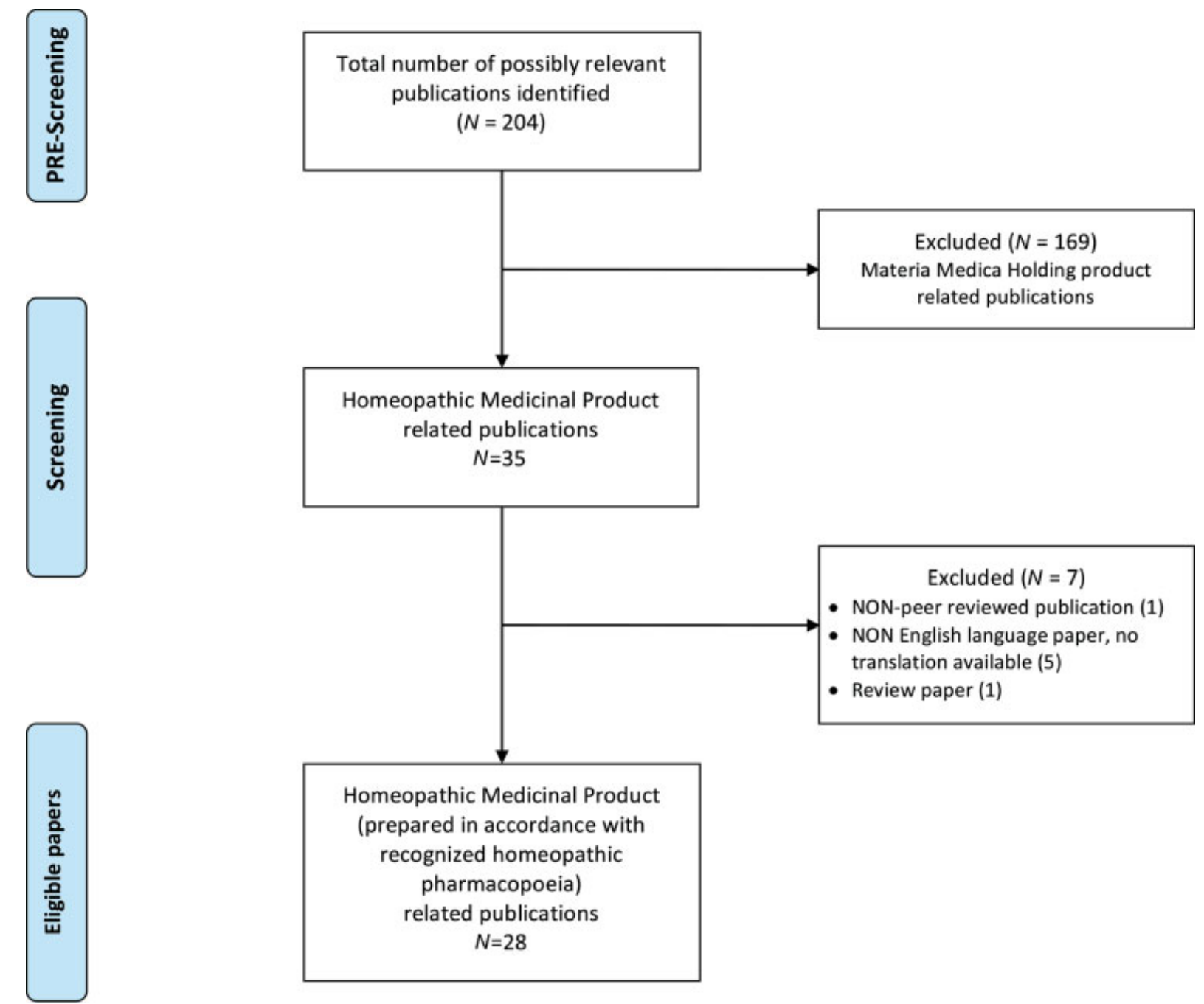

Fig. 1 Flow diagram. Selection process for eligible papers.

molecules. A clear majority of products ( 21 of 28 ) are derived from a combination of two or more signaling molecules.

Seventeen papers reported pre-clinical studies, and 11 reported clinical studies (six experimental, five observational). The direction of outcome is positive in the great majority of the papers, and the results are unclear in only two of the papers. Sixteen of the studies report a tentatively positive outcome, which was most commonly due to the inclusion of relatively few subjects in the clinical studies, positive but equivocal findings, non-significance of some of the outcome assessments, etc.

The clinical indications studied are given in - Table 2 , showing that the most commonly studied have been psoriasis, vitiligo, rheumatoid arthritis, respiratory allergies, polycystic ovary syndrome, and herpes.

\section{Discussion}

This scoping review found that there is a significant and growing body of evidence on the use of homeopathically prepared signaling molecules. The majority of the data involves pre-clinical research and only a minority involves clinical trials. Overall, the pre-clinical data are varied, and generally promising. A few of the clearly positive preclinical studies were published in high impact factor journals. Whilst the observational studies are promising, and the majority of clinical trials have tentatively positive results, further trials are needed, including high quality confirmatory clinical trials. Homeopathically prepared signaling molecules are used in a wide variety of clinical domains, with dermatology being the most advanced in terms of the accumulation of both pre-clinical and clinical studies.

The main strength of this review is that for the first time the studies on these types of products are summarized and brought to the attention of the homeopathy community via publication in a peer-reviewed homeopathy journal.

A limitation inherent to a scoping review is that the quality of the papers is not systematically assessed. A further limitation is that we may have missed articles only held in databases other than Scopus, such as for instance the Web of Science. However, Scopus is considered to be comprehensive in the domain of health-related topics, so we do not expect that we have missed a significant number of articles. 


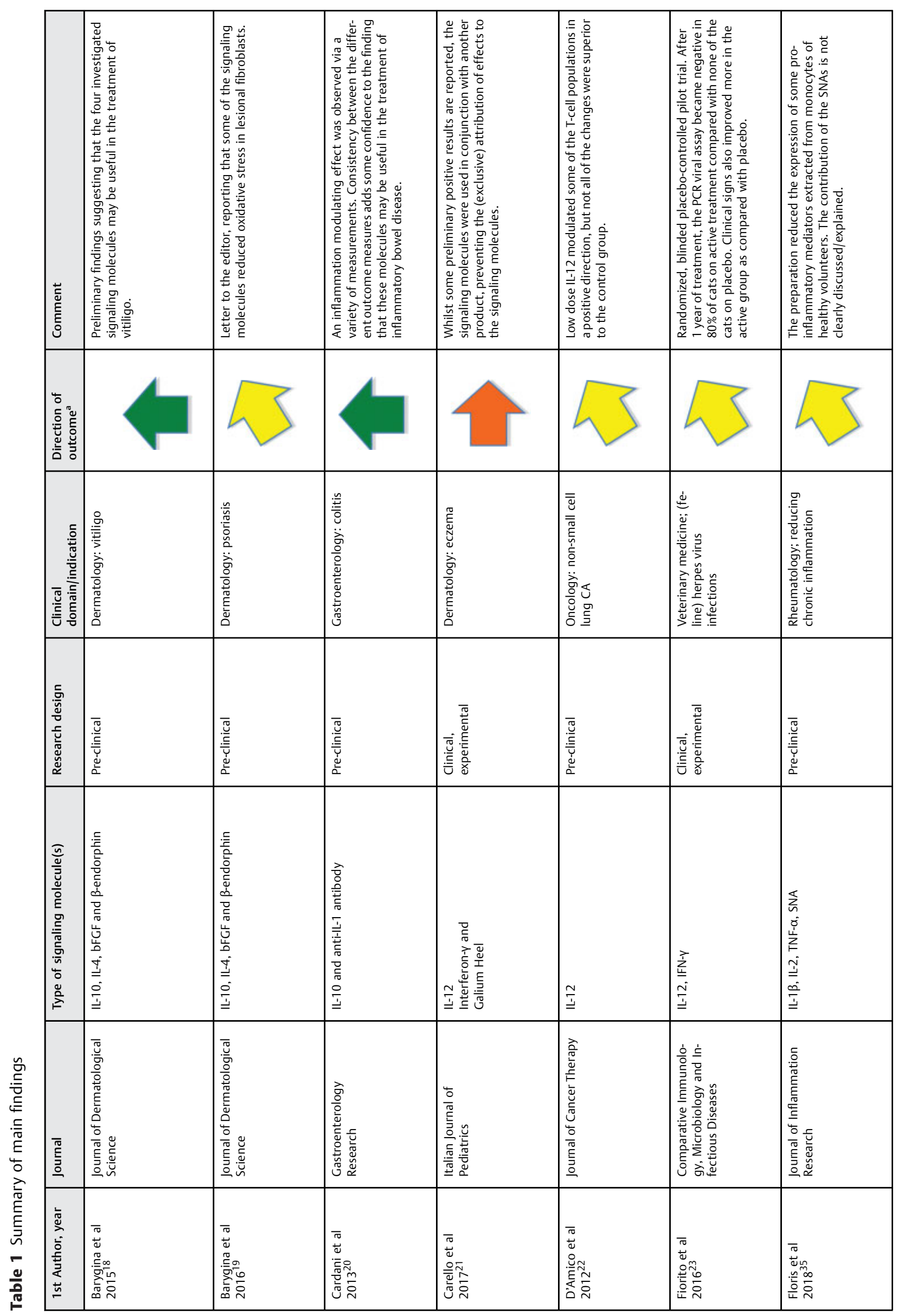




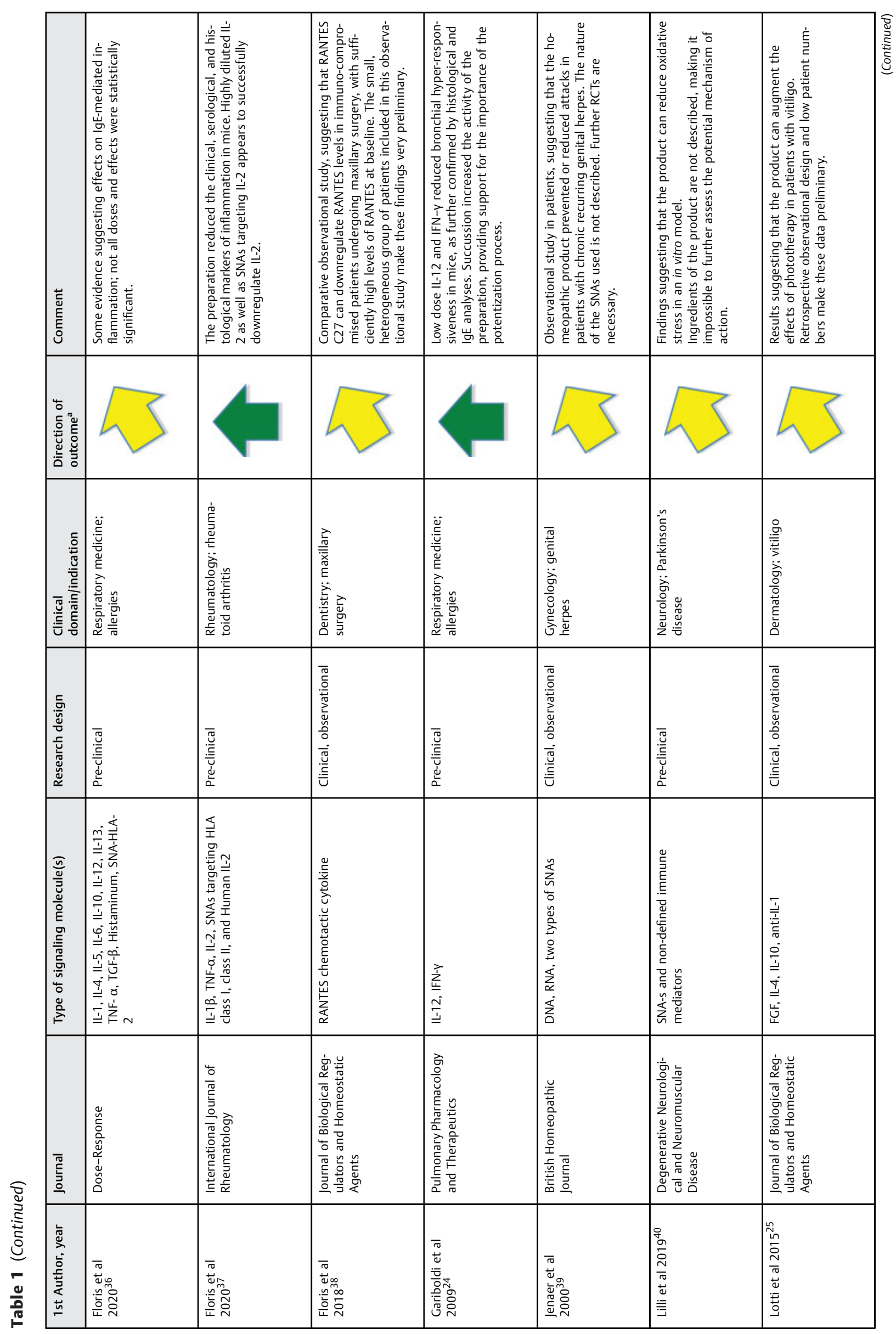




\begin{tabular}{|c|c|c|c|c|c|c|c|}
\hline 蒙 & 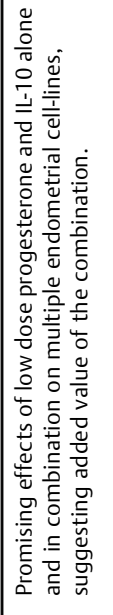 & 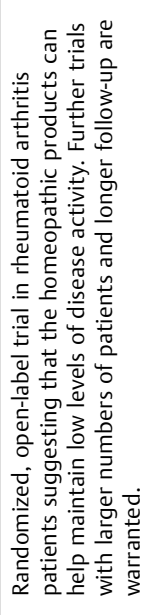 & 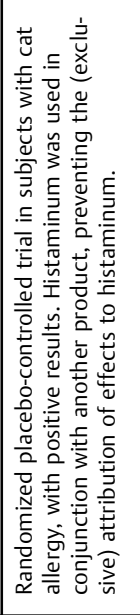 & 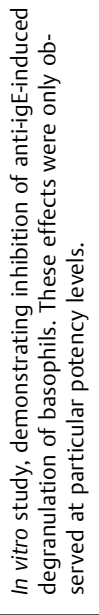 & 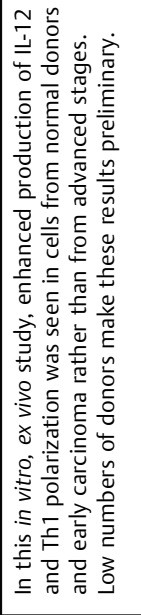 & 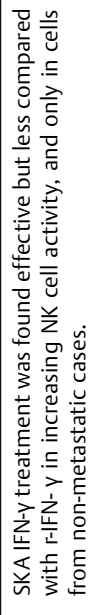 & 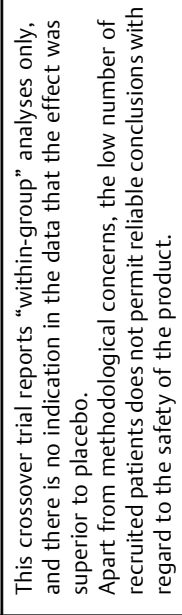 \\
\hline 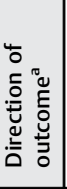 & & & & & & & \\
\hline 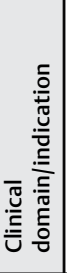 & 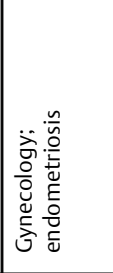 & 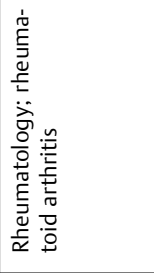 & 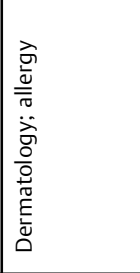 & 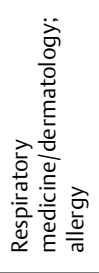 & 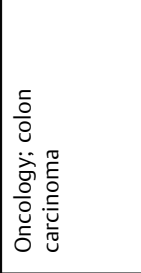 & 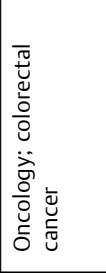 & 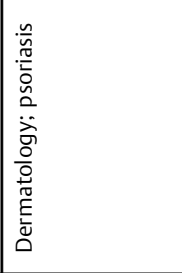 \\
\hline 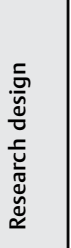 & 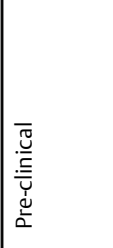 & 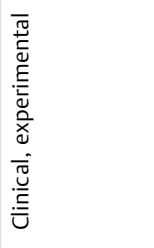 & 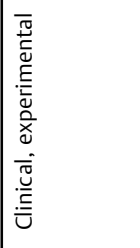 & 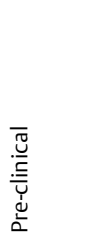 & 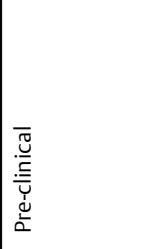 & 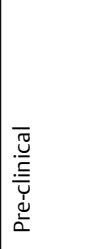 & 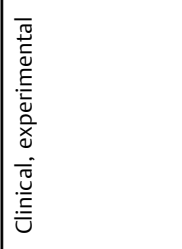 \\
\hline 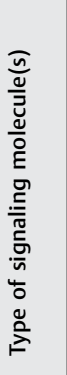 & 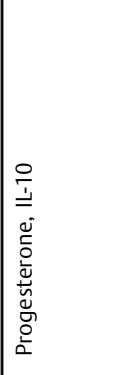 & 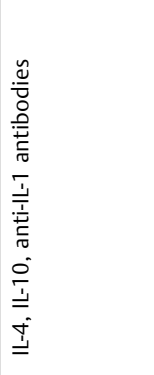 & 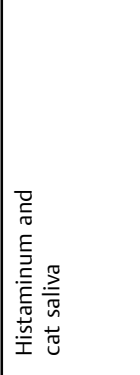 & 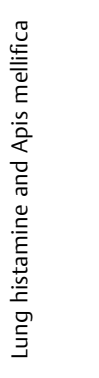 & $\begin{array}{l}\stackrel{\tilde{I}}{=} \\
\stackrel{\tilde{I}}{\stackrel{(}{I}}\end{array}$ & $\stackrel{\text { 咅 }}{\text {. }}$ & 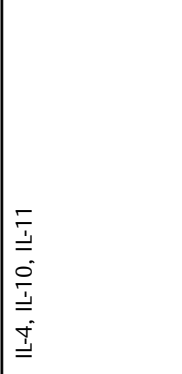 \\
\hline $\begin{array}{l}\overline{\bar{\sigma}} \\
\underline{\underline{z}}\end{array}$ & 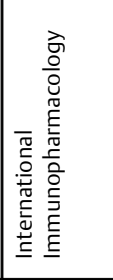 & 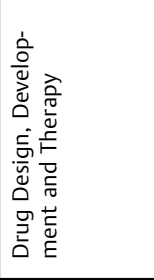 & 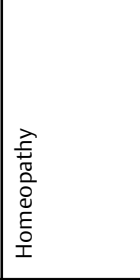 & 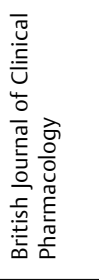 & 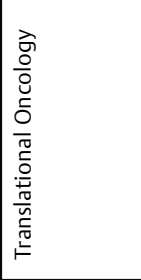 & 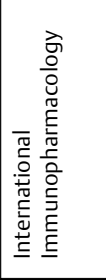 & 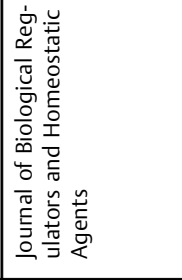 \\
\hline 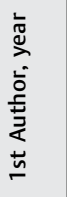 & 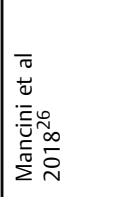 & 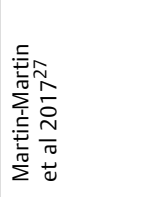 & 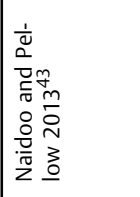 & 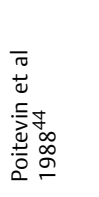 & 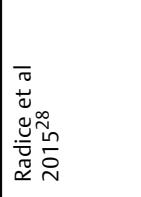 & 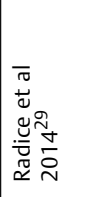 & 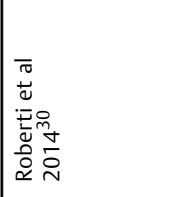 \\
\hline
\end{tabular}




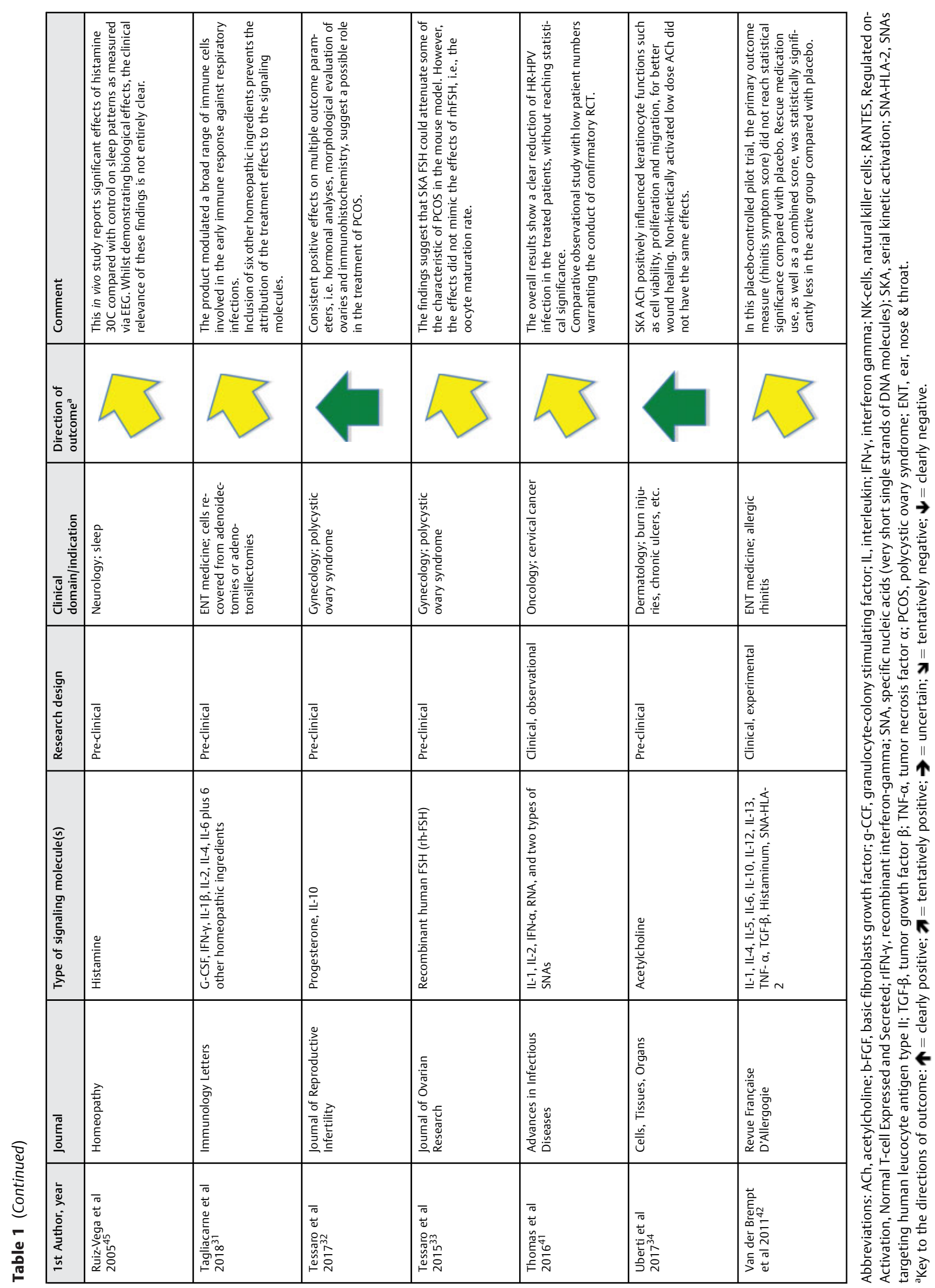


Table 2 Clinical indications of the studies

\begin{tabular}{|l|l|}
\hline Clinical indication & N studies \\
\hline Respiratory allergies & 4 \\
\hline Rheumatoid arthritis & 3 \\
\hline Polycystic ovary syndrome & 2 \\
\hline Psoriasis & 2 \\
\hline Vitiligo & 2 \\
\hline Cat allergy & 1 \\
\hline Cervical cancer & 1 \\
\hline Colitis & 1 \\
\hline Colon carcinoma & 1 \\
\hline Colorectal cancer & 1 \\
\hline Eczema & 1 \\
\hline Endometriosis & 1 \\
\hline Feline herpes virus infections & 1 \\
\hline Genital herpes & 1 \\
\hline Maxillary surgery & 1 \\
\hline Non-small cell lung cancer & 1 \\
\hline Parkinson's disease & 1 \\
\hline Sleep disturbance & 1 \\
\hline Tonsillitis/adenoiditis & 1 \\
\hline Wounds & 1 \\
\hline
\end{tabular}

Another weakness is that grading the direction of the evidence (as reported in -Table $\mathbf{1}$ ), based on independent review by four assessors followed by consensus discussion if appropriate, is a non-validated method. Despite this, we did feel it provided some added value to the results and conclusions as reported by the papers' authors (-Supplementary Table 1, available online only), especially because one of the main purposes of a scoping review is to provide the reader with a first orientation regarding the available data.

The high volume of studies related to Materia Medica Holding products came as a surprise to us. One of the reasons for this was that these products have not always been positioned on the market as "homeopathic medicinal products". From a regulatory point of view, this is strictly speaking correct, because only products that are manufactured in accordance with a recognized homeopathic pharmacopoeia are recognized as homeopathic medicinal products. ${ }^{46}$ However, from a practical point of view, these products have undergone a potentization process involving serial dilution alternating with kinetic agitation (referred to as releaseactivation), very similar to preparation in accordance with the German Homeopathic Pharmacopoeia (personal communication). Despite debate over the homeopathic nature of these products, ${ }^{47}$ most third parties point to a variety of arguments which support the notion that these products are homeopathic. $^{48}$ Some of these publications ${ }^{49-51}$ have even been retracted after the editors realized that the products investigated were homeopathic, in some cases even explicitly stating its homeopathic nature as the principal reason for the retraction. ${ }^{52-54}$ Whilst these papers therefore did not meet the inclusion criteria for this scoping review, we recognize as limitation that a significant number of relevant papers were not included. This gap should be addressed in a complementary scoping review.

The majority of the published material reported positive, or tentatively positive, results and all of the identified research was funded by the manufacturing companies concerned. Little or no research has been conducted to date by independent research groups without links to funding by the industries concerned. Publication bias can therefore not be excluded. We conducted a limited search on clinicaltrials.gov to see if we could identify any completed clinical trials (using the same search terms as described in the Methods section) that were not subsequently published. This search yielded one trial of 2LALERG in seasonal allergic rhinitis that was completed in $2016^{55}$ and that did not demonstrate superiority to placebo. Due to problems with the design and execution of this trial, its authors decided not to publish it (personal communication). In all scenarios, further confirmatory studies are needed.

Whilst the identified studies related to the therapeutic effectiveness of histamine were limited/inconclusive, it is worth mentioning that high dilution research on the effects of histamine on basophil degranulation is one of the bestestablished basic research models, and after more than 20 years of work on these models, the biological effects of $15-17 \mathrm{cH}$ potencies of histamine have been confirmed, ${ }^{56,57}$ and reproduced in large multi-center studies. ${ }^{58,59}$

The volume of the identified studies, and the response to some publications on these types of products in the scientific literature, clearly confirm the need to address the position of these products within homeopathy.

There is a need to formally assess the quality of the identified studies, using established criteria. Some further work may need to be done on the model validity of this category of papers from a homeopathy perspective. ${ }^{60}$ Further discussion would be needed in particular on how to assess the judgmental domains "Rationale for the choice of the particular homeopathic medicine" and "The extent to which homeopathic principles are reflected in the intervention".

We are of the opinion that these types of products potentially serve a bridge function between homeopathy and the natural sciences. Whilst many questions remain, it is clear that the homeopathic method of preparation is essential for releasing the "bioregulatory" action of these products. It is as yet unclear whether this is due to some sort of primary action of the homeopathically prepared substances and/or whether the homeopathic medicine acts as a catalyst for various biological processes. We feel that the group of signaling molecules is of particular interest in this regard because the scientific understanding of the actions of these molecules is still expanding rapidly, and this can provide a useful platform for linking homeopathic principles to modern pharmacology and biology. The ground is potentially fertile for this, because the use of these signaling molecules 
in higher doses based on a conventional pharmacological approach has largely failed, as illustrated for instance by attempts to use IFN- $\gamma .{ }^{61,62}$ Further discussion on what makes this new class of products homeopathic is urgently needed. The mere fact that these products have not undergone a classical Hahnemannian proving is, in our opinion, insufficient as an argument to dismiss this class of products as non-homeopathic. Interestingly, it is well documented that cytokines in higher than physiological concentrations are actually pathogenetic. ${ }^{63}$ Physiological as well as pathogenetic effects of these molecules may also provide some hints regarding their possible homeopathic uses. To our knowledge, the latter aspect has not been sufficiently explored. We also think that the time is right to move from a purely phenomenological approach to a more modern one that involves phenomenology as well as pathophysiological reasoning. Hahnemann himself tried to do something similar when endeavoring to integrate the dominant (now obsolete) miasma theory into the therapeutic framework of homeopathy.

It is conceivable that it will be possible to at least partly connect the therapeutic effects of homeopathically prepared signaling molecules to the emerging field of low-dose medicine ${ }^{64}$ and stimulation of hormetic regulation. On the other hand, experts in the field have pointed out that the observation of hormetic effects in itself does not constitute any sort of explanatory theory for the effects of homeopathic medicines. ${ }^{2,3}$ It is therefore important also to acknowledge the distinctions between homeopathy and hormesis. A detailed discussion on this topic is outside the scope of this article. Additionally, modern approaches have been proposed, ${ }^{65}$ which link the science of molecular networks with patients' autoregulatory capacity. Signaling molecules are pivotal elements in these molecular networks. This could therefore provide a modern framework for the stimulation of self-regulation that is aimed for in homeopathy. Further interactions with molecular biologists, immunologists and pharmacologists will be needed to advance this process.

As borne out by 200 years of homeopathy history, biological materials provide a key source for homeopathic medicinal products. Signaling molecules are amongst the most information dense molecules from a biological perspective. For instance, it has been demonstrated that IL-6 signaling requires only a few IL- 6 molecules. ${ }^{64}$ Therefore, from a homeopathy perspective, it is quite conceivable that these types of substances have therapeutic potential. Further steps to explore this potential are warranted.

Highlights

- Signaling molecules are pivotal elements in the body's self-regulating molecular networks.

- Homeopathically prepared signaling molecules have been used therapeutically for approximately five decades, though this fact is not well known.

- This scoping review systematically identified the available clinical and pre-clinical data for the first time.

- A surprising volume of promising data was identified.
- Further steps to explore the therapeutic use of homeopathically prepared signaling molecules are warranted.

\section{Supplementary material}

Supplementary Table 1. Main data: included studies. Supplementary Table 2. Main data: excluded studies.

\section{Authors' Contributions}

Both R.K. Manchanda and R. van Haselen were involved in the planning, conduct, analysis, and writing of the article. Drs. M. Gupta and A. Gupta were involved in the assessment of the literature papers and in the writing of the article. All authors agree to the contents of the manuscript.

\section{Conflict of Interest}

Robbert van Haselen has provided consultancy services to GUNA, one of the pharmaceutical companies manufacturing and distributing homeopathically prepared signaling molecules. There is no conflict of interest for the other authors.

\section{Acknowledgements}

The authors thank Guna, Labo'Life, and Materia Medica Holding for their support with identifying studies and available translations.

\section{References}

1 López-Otín C, Kroemer G. Hallmarks of health. Cell 2021; 184:33-63

2 Bellavite P, Marzotto M, Olioso D, Moratti E, Conforti A. Highdilution effects revisited. 2. Pharmacodynamic mechanisms. Homeopathy 2014;103:22-43

3 Calabrese EJ, Jonas WB. Homeopathy: clarifying its relationship to hormesis. Hum Exp Toxicol 2010;29:531-536

4 Van Wijk R, Wiegant FA. Postconditioning hormesis and the similia principle. Front Biosci (Elite Ed) 2011;3:1128-1138

5 Krause CD, Pestka S. Evolution of the Class 2 cytokines and receptors, and discovery of new friends and relatives. Pharmacol Ther 2005;106:299-346

6 Scheller J, Chalaris A, Schmidt-Arras D, Rose-John S. The pro- and anti-inflammatory properties of the cytokine interleukin-6. Biochim Biophys Acta 2011;1813:878-888

7 Reilly D, Taylor MA, Beattie NGM, et al. Is evidence for homoeopathy reproducible? Lancet 1994;344:1601-1606

8 WHO. Safety Issues in the Preparation of Homeopathic Medicines. WHO Publications; 2009:51

9 Tricco AC, Lillie E, Zarin W, et al. PRISMA extension for scoping reviews (PRISMA-SCR): checklist and explanation. Ann Intern Med 2018;169:467-473

10 Genazzani A, Despini G, Chierchia E, Benedetti C, Prati A. Pharmacological and integrative treatment of stress-induced hypothalamic amenorrhea. In: Genazzani A, Tarlatzis B, eds. Cham: Frontiers in Gynecological Endocrinology: Volume 3: Ovarian Function and Reproduction-From Needs to Possibilities. International Society of Gynecological Endocrinology; 2016:69-84

11 Lotti T. Successful combination treatment for psoriasis with phototherapy and low-dose cytokines: A spontaneous, retrospective observational clinical study. Hautarzt 2015;66:849-854

12 Lotti T, Hercogova J, Fabrizi G. Advances in the treatment options for vitiligo: activated low-dose cytokines-based therapy. Review Expert Opin Pharmacother 2015;16:2485-2496 
13 Luchetti P. Increasing of visual function in patients with retinal atrophy treated with drugs of low dose medicine. Monocentric retrospective observational study. Minerva Oftalmol 2014;56:53-61

14 Rivkina T, Hercogova J, Lotti T. P.N.E.I.: life and death of skin cells. A new paradigm in the treatment of vitiligo: the low dose cytokines therapy. Dermatol Ther (Heidelb) 2016;29:134-135

15 Grauwet DJ. Infecciones genitales por VPH tratadas por microinmunoterapia. Rev Méd Homeopat 2011;4:103-105

16 Boucinhas JC, De Madeiros Boucinhas ID. Prophylaxie des crises d'asthme bronchique chez l'enfant par l'usage de Poumon histamine 5 CH. Homeopath Fr 1990;78:35-39

17 Nolleveaux MA. Interet de la prescription d'APP (Apis $15 \mathrm{cH}$, Pulmo-Histaminum $15 \mathrm{cH}$, Pollantinum $30 \mathrm{cH}$ ) dans la rhinite allergique. Observations cliniques en pratique journaliere. Homeopath Fr 1992;80:24-33

18 Barygina V, Becatti M, Lotti T, Moretti S, Taddei N, Fiorillo C. Treatment with low-dose cytokines reduces oxidative-mediated injury in perilesional keratinocytes from vitiligo skin. J Dermatol Sci 2015;79:163-170

19 Barygina V, Becatti M, Lotti T, Taddei N, Fiorillo C. Low dose cytokines reduce oxidative stress in primary lesional fibroblasts obtained from psoriatic patients. J Dermatol Sci 2016;83:242-244

20 Cardani D, Dusio GF, Luchini P, Sciarabba M, Solimene U, Rumio C. Oral administration of interleukin-10 and anti-IL-1 antibody ameliorates experimental intestinal inflammation. Gastroenterol Res 2013;6:124-133

21 Carello R, Ricottini L, Miranda V, et al. Long-term treatment with low-dose medicine in chronic childhood eczema: a double-blind two-stage randomized control trial. Ital J Pediatr 2017;43:78

22 D’Amico L, Ruffini E, Ferracini R, Roato I. Low dose of IL-12 stimulates $\mathrm{T}$ cell response in cultures of PBMCs derived from non small cell lung cancer patients. J Cancer Ther 2012;3:337-342

23 Fiorito F, Cantiello A, Granato GE, et al. Clinical improvement in feline herpesvirus 1 infected cats by oral low dose of interleukin12 plus interferon-gamma. Comp Immunol Microbiol Infect Dis 2016;48:41-47

24 Gariboldi S, Palazzo M, Zanobbio L, et al. Low dose oral administration of cytokines for treatment of allergic asthma. Pulm Pharmacol Ther 2009;22:497-510

25 Lotti T, Hercogova J, Wollina U, et al. Vitiligo: successful combination treatment based on oral low dose cytokines and different topical treatments. J Biol Regul Homeost Agents 2015;29 (Suppl 1):53-58

26 Mancini F, Milardi D, Carfagna P, et al. Low-dose SKA Progesterone and Interleukin-10 modulate the inflammatory pathway in endometriotic cell lines. Int Immunopharmacol 2018;55:223-230

27 Martin-Martin LS, Giovannangeli F, Bizzi E, et al. An open randomized active-controlled clinical trial with low-dose SKA cytokines versus DMARDs evaluating low disease activity maintenance in patients with rheumatoid arthritis. Drug Des Devel Ther 2017;11:985-994

28 Radice E, Bellone G, Miranda V. Enhancement of the immunostimulatory functions of ex vivo-generated dendritic cells from early-stage colon cancer patients by consecutive exposure to low doses of sequential-kinetic-activated IL-4 and IL-12. A preliminary study. Transl Oncol 2015;8:327-338

29 Radice E, Miranda V, Bellone G. Low-doses of sequential-kineticactivated interferon- $\gamma$ enhance the ex vivo cytotoxicity of peripheral blood natural killer cells from patients with early-stage colorectal cancer. A preliminary study. Int Immunopharmacol 2014;19:66-73

30 Roberti ML, Ricottini L, Capponi A, et al. Immunomodulating treatment with low dose interleukin-4, interleukin-10 and interleukin-11 in psoriasis vulgaris. J Biol Regul Homeost Agents 2014; 28:133-139

31 Tagliacarne SC, Valsecchi C, Benazzo M, et al. Low-dose multicomponent medication modulates humoral and cellular immune response in an ex-vivo study on children subjected to adenoid surgery. Immunol Lett 2018;203:95-101
32 Tessaro I, Modina S, Lodde V, et al. Ultra-low doses of follicle stimulating hormone and progesterone attenuate the severity of polycystic ovary syndrome features in a hyperandrogenized mouse model. J Reprod Infertil 2017;18:288-297

33 Tessaro I, Modina SC, Franciosi F, et al. Effect of oral administration of low-dose follicle stimulating hormone on hyperandrogenized mice as a model of polycystic ovary syndrome. J Ovarian Res 2015;8:64

34 Uberti F, Bardelli C, Morsanuto V, Ghirlanda S, Cochis A, Molinari C. Stimulation of the nonneuronal cholinergic system by highly diluted acetylcholine in keratinocytes. Cells Tissues Organs 2017; 203:215-230

35 Floris I, Appel K, Rose T, Lejeune B. 2LARTH ${ }^{\circledR}$, a micro-immunotherapy medicine, exerts anti-inflammatory effects in vitro and reduces TNF- $\alpha$ and IL-1 $\beta$ secretion. J Inflamm Res 2018;11:397-405

36 Floris I, Chenuet P, Togbe D, Volteau C, Lejeune B. Potential role of the micro-immunotherapy medicine 2LALERG in the treatment of pollen-induced allergic inflammation. Dose Response 2020; 18:1559325820914092

37 Floris I, García-González V, Palomares B, Appel K, Lejeune B. The micro-immunotherapy medicine 2 LARTH ${ }^{\circledR}$ reduces inflammation and symptoms of rheumatoid arthritis in vivo. Int J Rheumatol 2020;2020:1594573

38 Floris I, Lechner J, Lejeune B. Follow-up of patients with systemic immunological diseases undergoing fatty-degenerative osteolysis of the jawbone surgery and treated with RANTES 27CH. J Biol Regul Homeost Agents 2018;32:37-45

39 Jenaer M, Henry MF, Garcia A, Marichal B. Evaluation of 2LHERP in preventing recurrences of genital herpes. Institut International 3IDI. Br Homeopath J 2000;89:174-177

40 Lilli NL, Révy D, Robelet S, Lejeune B. Effect of the microimmunotherapy medicine 2 LPARK $^{\circledR}$ on rat primary dopaminergic neurons after 6-OHDA injury: oxidative stress and survival evaluation in an in vitro model of Parkinson's disease. Degener Neurol Neuromuscul Dis 2019;9:79-88

41 Thomas G, Cluzel H, Lafon J, Bruhwyler J, Lajeune B. Efficacy of

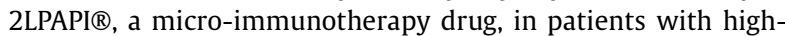
risk papillomavirus genital infection. Adv Infect Dis 2016;6:7-14

42 Van der Brempt X, Cumps J, Capieaux E. Efficacité clinique du $2 \mathrm{~L} 囚 A L E R G$, un nouveau traitement de type immunomodulateur par voie sublinguale dans le rhume des foins: une étude en double insu contre placebo. Rev Fr Allergol 2011;51:430-436

43 Naidoo P, Pellow J. A randomized placebo-controlled pilot study of Cat saliva $9 \mathrm{cH}$ and Histaminum $9 \mathrm{cH}$ in cat allergic adults. Homeopathy 2013;102:123-129

44 Poitevin B, Davenas E, Benveniste J. In vitro immunological degranulation of human basophils is modulated by lung histamine and Apis mellifica. Br J Clin Pharmacol 1988; 25:439-444

45 Ruiz-Vega G, Poitevin B, Pérez-Ordaz L. Histamine at high dilution reduces spectral density in delta band in sleeping rats. Homeopathy 2005;94:86-91

46 Herr G, Natz A, van Haselen R. The coherency of regulatory requirements for homeopathic medicinal products in the EU and the EAEU. Eur Pharmaceut Law Rev 2019;3:58-72

47 Andrianova E, Putilovskiy M. Efficacy and safety of Ergoferon versus oseltamivir: reply to the Letter to the Editor. Int J Infect Dis 2019;89:190-192

48 International Journal of Endocrinology. Expression of concern on "Subetta treatment increases adiponectin secretion by mature human adipocytes in vitro". Int J Endocrinol 2019;2019:6595878

49 Petrova NV, Emelyanova AG, Gorbunov EA, et al. Efficacy of novel antibody-based drugs against rhinovirus infection: in vitro and in vivo results. Retracted. Antiviral Res 2017;142:185-192

50 Skarnovich MA, Emelyanova AG, Petrova NV, et al. Activity of ergoferon against lethal influenza $A(H 3 N 2)$ virus infection in mice. Antivir Ther 2017;22:345-351

51 Tarasov SA, Zarubaev VV, Gorbunov EA, Sergeeva SA, Epstein OI Activity of ultra-low doses of antibodies to gamma-interferon 
against lethal influenza $A(H 1 N 1) 2009$ virus infection in mice. Retracted. Antiviral Res 2012;93:219-224

52 Petrova NV, Emelyanova AG, Gorbunov EA, et al. Retraction notice to "Efficacy of novel antibody-based drugs against rhinovirus infection: in vitro and in vivo results". Antiviral Res 2019;164:176

53 Skarnovich MA, Emelyanova AG, Petrova NV, et al. Retraction: Activity of ergoferon against lethal influenza A (H3N2) virus infection in mice. Antivir Ther 2019;24:235

54 Tarasov SA, Zarubaev VV, Gorbunov EA, Sergeeva SA, Epstein OI. Retraction notice to "Activity of ultra-low doses of antibodies to gamma-interferon against lethal influenza $A(H 1 N 1) 2009$ virus infection in mice". Antiviral Res 2019;164:177

55 ClinicalTrials.gov. Efficacy of 2LALERG (Homeopathic Drug) in allergic rhinitis related to grass pollen (LLB-2016-01). Accessed January 6, 2021 at: https://www.clinicaltrials.gov/ct2/show/results/NCT02690935? term=2LALERG\&draw $=2 \&$ rank $=1$

56 Belon P, Cumps J, Ennis M, et al. Histamine dilutions modulate basophil activation. Inflamm Res 2004;53:181-188

57 Lorenz I, Schneider EM, Stolz P, Brack A, Strube J. Sensitive flow cytometric method to test basophil activation influenced by homeopathic histamine dilutions. Forsch Komplementarmed Klass Naturheilkd 2003;10:316-324

58 Chirumbolo S, Brizzi M, Ortolani R, Vella A, Bellavite P. Inhibition of CD203c membrane up-regulation in human basophils by high dilutions of histamine: a controlled replication study. Inflamm Res 2009;58:755-764

59 Sainte-Laudy J, Belon P. Inhibition of basophil activation by histamine: a sensitive and reproducible model for the study of the biological activity of high dilutions. Homeopathy 2009; 98:186-197

60 Mathie RT, Roniger H, Van Wassenhoven M, et al. Method for appraising model validity of randomised controlled trials of homeopathic treatment: multi-rater concordance study. BMC Med Res Methodol 2012;12:49

61 Panitch HS, Hirsch RL, Schindler J, Johnson KP. Treatment of multiple sclerosis with gamma interferon: exacerbations associated with activation of the immune system. Neurology 1987; 37:1097-1102

62 van Zandwijk N, Groen HJM, Postmus PE, et al. Role of recombinant interferon-gamma maintenance in responding patients with small cell lung cancer. A randomised phase III study of the EORTC Lung Cancer Cooperative Group. Eur J Cancer 1997; 33:1759-1766

63 Raphael I, Nalawade S, Eagar TN, Forsthuber TG. T cell subsets and their signature cytokines in autoimmune and inflammatory diseases. Cytokine 2015;74:5-17

64 Bernasconi S. Low dose medicine: theoretical background and scientific evidence. Ital J Pediatr 2018;44:23

65 Goldman AW, Burmeister Y, Cesnulevicius K, et al. Bioregulatory systems medicine: an innovative approach to integrating the science of molecular networks, inflammation, and systems biology with the patient's autoregulatory capacity? Front Physiol 2015;6:225

66 Hansen MB. Interleukin-6 signaling requires only few IL-6 molecules: relation to physiological concentrations of extracellular IL-6. Immun Inflamm Dis 2020;8:170-180 